\title{
Unmitigated Agency and Unmitigated Communion: An Analysis of the Negative Components of Masculinity and Femininity ${ }^{1}$
}

\author{
David M. Buss ${ }^{2}$ \\ University of Michigan
}

The negative components of masculinity and femininity, conceptualized by Spence and her colleagues (1979) as unmitigated agency and unmitigated communion, were explored by examining dominant and submissive acts used in their expression. In three separate sessions, subjects $(N=129)$ completed scales designed to measure these constructs, a Dominance Act Report, and a Submissiveness Act Report. Dominant acts used in the expression of unmitigated agency involved the formation of separations (e.g., making decisions without consulting the others involved in them), narcissistic self-assertion (e.g., telling others to perform one's menial tasks), and self-protection (e.g., bluffing one's way out of an embarrassing situation). Submissive acts used in the expression of unmitigated communion involved failing to make normatively appropriate agentic responses (e.g., walking out of a store knowing that one had been short-changed) and subjugating personal desires to group wishes (e.g., giving up vacation plans in deference to the preferences of others). Discussion focuses on elaborating the concepts of unmitigated agency and unmitigated communion.

Bakan (1966) conceptualizes two modes of existence-agency and communion - that presumably characterize all living forms. Agency involves self-enhancement and self-assertion, whereas communion entails group participation

\footnotetext{
'This article was completed while the author was a Fellow at the Center for Advanced Study in the Behavioral Sciences. Support was provided by NIMH Grant MH-44206-01, NSF Grant BNS98-00864, and the Gordon P. Getty Trust. The author thanks Kenneth H. Craik and Carolyn Phinney for their valuable suggestions on earlier drafts of this article.

${ }^{2}$ To whom correspondence should be addressed at Department of Psychology, University of Michigan, Ann Arbor, Michigan 48109-1346.
} 
and cooperation with others. The agentic person forms separations; the communal person creates unions. The agentic person isolates self from others; the communal person embeds the self in a collective. The agenic person exists for the self; the communal person provides for the group. Umitigated agency, according to Bakan, propels both the individual and society toward destruction and death. The mitigation of agency with communion, therefore, provides a proper goal of the individual throughout life (Bakan, 1966, p. 236).

These distinctions, and similar ones (e.g., Erikson, 1964; Guttman, 1965; Parsons \& Bales, 1955; Witkin, 1974), have been advanced to characterize differences between males and females (Bakan, 1966; Block, 1973; Carlson, 1971; Spence \& Helmreich, 1978). Empirical research, however, has lagged far behind the elaboration of these conceptualizations, although there are several exceptions. Carlson (1971), for example, classified self-reported instances of affect as agentic, communal, or mixed. The affective instances reported by males were significantly more agentic than were those reported by females, supporting the notion of sex differences in modality of expression.

In another line of research, unmitigated agency and unmitigated communion have been linked with undesirable psychological and physical health outcomes. Persons whose lives may be characterized by unmitigated agency (e.g., as coded from interviews about the workplace and home) seem prone to physical illness, whereas those characterized by unmitigated communion might be susceptible to depression and despair (Malley \& Stewart, 1988; Stewart \& Malley, 1987; Stewart \& Salt, 1981). The presence of both components apparently neutralizes the deliterious health effects of either when present alone (see also Baruch, Barnett, \& Rivers, 1983; Chodorow, 1987; Malley, 1989; Veroff, Kulka, \& Douvan, 1981 for analyses of the agentic and communal aspects of work and marriage).

The presence of sex differences in agentic and communal modes may be one source of conflict between men and women. Buss (1989), for example, found substantial sex differences in the complaints that men and women had about each other. Women more than men complained that their partners were emotionally constricted failing to communicate their inner feelings and thoughts. Men more than women, in contrast, complained that their partners were too emotionally expressive and labile.

Another line of research has examined sex differences in the evaluation and reported performance of dominant acts (Buss, 1981). In one study, it was found that agentic dominant acts (e.g., getting others to perform one's menial chores) were judged by males more than by females to be relatively socially desirable. Communal acts (e.g., participation in community activities) were judged to be more desirable by female than by males raters. A second study found that dominant males tended to report expressing dominance through both self-serving agentic acts (e.g., demanding that errands 
be run for them) and group-oriented acts (e.g., livening up a dull party). Dominant females, on the other hand, tended to express their dominance primarily through group-enhancing communal acts, and less often reported performing the self-serving acts characteristic of dominant males.

Although it may be relatively easy to identify the acts implicated by the concept of unmitigated agency, it is less clear what is meant by "unmitigated communion." Indeed, Bakan's discussion focuses primarily on the manner in which agency is expressed in unmitigated form (e.g., through aggression, sexual promiscuity, and suicide) and the ways in which agency may be tempered by communion. But is it possible to be too communal, too group-oriented, or too concerned with establishing harmony within the social network? Although he does not develop this line of thought, Bakan does answer in the affirmative by suggesting that unmitigated communion is linked with "primary" masochism, a concept advanced by Freud (1950). Unmitigated communion may entail extreme subjugation of the self to the demands and exigencies of the group.

The purpose of the present research was to examine these conceptualizations by exploring the manner in which unmitigated agency and unmitigated communion are expressed in dominant and submissive acts. Based on the studies reported by Buss (1981) it was reasoned that the domain of dominance, broadly sampled, consists of acts of agency, both mitigated and unmitigated by communion. Thus, a subset of dominant acts involves the expression of dominance for self-gain, self-enhancement, and self-promulgation. Another subset entails acts of agency, the purpose of which is to facilitate the functioning and cohesion of the group. Similarly, it was reasoned that the domain of submissiveness may contain acts involving excessive yielding to the group at the expense of the self. Masochistic self-subjugation to others can be viewed as reflecting unmitigated communion - the preservation of harmony within the group (or the avoidance of overt group conflict) untempered by agentic actions. Another subset may entail acts of communion, the purpose of which is to facilitate group harmony, but without self-depreciation in the process.

The measures employed to assess unmitigated agency and unmitigated communion were those developed by Spence, Helmreich, and Holahan (1979) explicitly for this purpose. The scale designed to measure unmitigated agency (M-) consists of attributes judged to be agentic in content, socially undesirable in both sexes, and attributed more often to males than to females. The Fcscale, designed to assess unmitigated communion, consists of attributes judged to be communal in content, socially undesirable in both sexes, and attributed more frequently to females than to males. A third scale (Fva-), developed by Spence et al. (1979) to assess a construct unanticipated on theoretical grounds, involves verbal passive-aggressiveness. This scale was included in the present study because it appears to combine the elements of unmitigated 
agency and unmitigated communion. That is, aggression can be viewed as instrumental behavior for self-gain at the expense of others, and extreme passivity may entail excessive yielding to the group, untempered by the agentic component. Predictions follow directly from the conceptual framework just elaborated. It was expected that (1) persons scoring high on M- would report performing acts within the domain of dominance that involve self-gain, self-enhancement, and self-promulgation at the expense of the larger group; (2) persons scoring high on Fc- would report performing acts within the domain of submissiveness that involve self-effacement and masochism-communal acts that serve to maintain harmony within the group at the expense of the individual performing them; and (3) persons scoring high on Fva- would report performing acts of both unmitigated agency and of unmitigated communion.

\section{METHOD}

\section{Subjects}

One-hundred and twenty-nine undergraduates ( 72 females and 57 males) participated in the present study. Subjects received experimental credit and individual personality feedback in return for their participation.

\section{Independent Measures}

The independent measures consisted of the three scales assessing the negative components of masculinity (M-) and femininity (Fc- and Fva-) composing the Extended Personal Attributes Questionnaire (EPAQ). Sample items from these scales are: M- (arrogant, boastful, greedy, cynical), Fc(spineless, servile, gullible, subordinates self to others), Fva- (whiny, complaining, fussy, nagging). Subjects read each item and rate its descriptiveness with regard to themselves on a 5-point scale, ranging from "very" to "not at all" characteristic. Further details about these scales may be obtained from Spence et al. (1979).

\section{Act Reports}

The dependent measures consisted of two Act Reports, containing 100 acts each. The first Act Report contained the 100 acts generated by Buss and Craik (1980) for their studies of dominance. The second Act Report contained 
100 acts, nominated as being within the domain of submissiveness, generated for the present and companion studies. The nomination procedures are described in detail elsewhere (Buss \& Craik, 1980). Examples of acts nominated as dominant are: "he demanded a backrub," "she confronted someone about a rumor he had spread," "he decided which TV programs they would watch," and "she assigned roles and got the game going." Examples of acts nominated as submissive are: "he followed his religious counselor's instructions without question," "she accepted verbal abuse without defending herself," "he drank a lot at the party when the others gave him a hard time," and "she let her partner choose the movie they would see."

For the present study, each act was transformed from the third-person singular to the first person singular (e.g., "she let her partner chose..." became "I let my partner chose..."). The act report measures were labeled $A c t$ Report $C$ and Act Report $D$, and not explicitly labeled by the category of acts being assessed. Within the Act Reports, participants were asked to check "yes" or "no" according to whether or not they had ever performed each act. If the answer was "yes" they were asked to indicate the relative frequency with which they performed each act on a three-point scale, ranging from "rarely" to "often."

\section{Procedure}

Data gathering occurred in three separate session, each separated by approximately a one-week interval. A week was allowed between each of the three sessions in order to minimize the operation of response sets. In the first session, participants completed Act Report $C$ (dominant acts); in the second session, they completed Act Report $D$ (submissive acts); in the third session, the EPAQ was completed. Other measures were included within each session for companion studies.

\section{RESULTS}

\section{M- and Dominant Acts}

The M- scale (unmitigated agency) was correlated with reported performance of each act on the dominance Act Report for the sexes separately. Table I presents the correlations that reached significance (two-tailed test) beyond the .05 level.

The acts shown in Table I appear to portray the types of behaviors implicated by Bakan's concept of unmitigated agency. The highest correlations 
Table I. Dominant Act Correlates of M- (Unmitigated Agency)

\begin{tabular}{ll}
\hline $\mathrm{r}$ & \multicolumn{1}{c}{ Acts } \\
\hline $.44^{* * *}$ & I mades $(N=57)$ \\
$.40^{* *}$ & I told others to perform menial tasks rather than doing them myself. \\
$.39^{* *}$ & I bluffed my way out of an embarrassing situation. \\
$.33^{*}$ & I quickly corrected my friends's mistake publicly. \\
$.32^{*}$ & I ridiculed her in the presence of a group. \\
$.31^{*}$ & I set goals for the groups. \\
$.31^{*}$ & I persuaded him to do something he didn't want to do. \\
$.29^{*}$ & I organized a protest meeting. \\
$.29^{*}$ & I challenged someone to discuss her position. \\
$.29^{*}$ & I told a long story to entertain others. \\
$.28^{*}$ & I readily used the authority of my position. \\
$.28^{*}$ & I managed to get my own way. \\
& \\
$.32^{* *}$ & I refused to accept a compromise. \\
$.30^{*}$ & I spoke with a loud, firm voice. \\
$.29^{*}$ & I used my fists in order to get my way. \\
$.29^{*}$ & I issued orders that got the group organized. \\
$.29^{*}$ & I made decisions without consulting the others involved in them. \\
$.28^{*}$ & When someone cut ahead of me in line, I protested loudly. \\
$.24^{*}$ & I yelled in order to get my way. \\
$.24^{*}$ & I refused to compromise despite considerable group pressure. \\
$-.24^{*}$ & I decided which TV programs we would watch. \\
\hline$* * * p<.001$. \\
$* * p<.01$.
\end{tabular}

of $\mathrm{M}$ - for the male sample are with the acts "I made decisions without consulting the others involved in them" and "I told others to perform menial tasks rather than doing them myself." These acts clearly illustrate a separation of self from the group, where the group should be involved, and manipulation of others for selfish ends. A similar pattern emerges in the female sample, although the magnitude of the correlations is slightly lower than for the male sample. Acts involving refusing, ordering, complaining, and yelling, mostly for selfish purposes, portray the concern with self and the formation of separations characteristic of unmitigated agency.

There appear to be subtle differences between the acts correlated with $\mathrm{M}$ - for the male and female samples, although there is overlap. The acts cor- 
related in the male sample seem to involve calm manipulation of others. The acts correlated with $\mathbf{M}$ - for the female sample, however, appear to contain more overt, acrimonious, and perhaps ineffective attempts to manipulate others. Whereas males scoring high on M- report persuading others, organizing others, and managing others in order to get their way, high scoring females report using their fists, issuing orders, complaining, and yelling in order to get their way. Although both sets of acts cannote a sense of agency, the set of acts for the female sample contains a stridency in tone that is absent from the male act correlates.

\section{Fc- and Submissive Acts}

The Fc- scale (unmitigated communion) was correlated with reported performance of each act on the submissive act report for the sexes separately. Table II presents the correlations that reached significance (two-tailed test) beyond the .05 level.

In the conceptual framework elaborated earlier, it was suggested that unmitigated communion may involve self-effacement and self-subjugation approaching masochism. The acts shown in Table II, for both sexes, appear to contain these elements. Tolerating insults, apologizing repeatedly for mistakes, agreeing that one is wrong (even though not wrong) and accepting verbal abuse without defending onseself, suggest actions designed to avoid conflict within the group at the expense of the individual performing these acts.

Several features of these acts merit emphasis. First, many of these acts seem to entail abstaining from an agentic response when one is clearly called for. Thus, acts such as tolerating insults, listening quietly to criticism, not talking back when scolded by a friend, failing to express the wish to be repaid a loan, and walking out of a store knowing that one has been short-changed, all appear to involve the failure to make appropriate agentic responses called for by the situation. A second component of these submissive acts entails acting against ones wishes, that is, subjugating personal desires to group pressures. Acts such as giving up vacation plans in deference to the preferences of others, agreeing that one is wrong (even though not wrong), continuing one's schooling because of parental wishes, and eating out because others wanted to (even though not hungry), all involve the performance of actions that perhaps preserve group harmony, but at the psychological cost of selfabnegation. Together, these two elements - absence of normatively appropriate agentic responses and presence of masochistic communal responses-identify the criterial features of unmitigated communion. 
Table II. Submissive Act Correlates of Fc- (Unmitigated Communion)

\begin{tabular}{ll}
\hline $\mathrm{r}$ & \multicolumn{1}{c}{ Acts } \\
\hline & \\
$.42^{* * *}$ & I accepted verbal abuse without defending myself. \\
$.37^{* *}$ & I tolerated the insult from my classmate without retorting. \\
$.37^{* *}$ & I listened quietly when my parents said my hair was ugly. \\
$.33^{*}$ & Although my friends thought my partner humiliated me, I dated her again. \\
$.33^{*}$ & I said "OK" to every suggestion that was offered about my project. \\
$.31^{*}$ & I moved quietly aside when a passerby brushed against me in the corridor. \\
$.30^{*}$ & I did not talk back when my friend scolded me. \\
$.30^{*}$ & I continued to apologize for the minor mistake. \\
$.29^{*}$ & I used my car for the group trip and didn't ask for gas money from the others. \\
$.28^{*}$ & I gave up my own vacation wishes in deference to the preference of my friends. \\
$.28^{*}$ & I agreed I was wrong even though I wasn't. \\
$.27^{*}$ & I gave money to a friend, but failed to express my wish to be repaid. \\
$.27^{*}$ & I let someone cut into the parking space I was waiting for.
\end{tabular}

Females $(N=67)$

$.41^{* * *}$ Although not really interested in it, I watched the big TV show because everyone would be talking about it the next day.

$.36^{* *} \quad$ I continued my schooling because my father wanted me to.

$.36 *$ I went out to eat, not because I was hungry, but because the others wanted to go then.

$.35 * * \quad$ I took the class just because my friend did.

$.30^{*} \quad$ Even though the selection of the new lamp became a test of will, I ultimately gave in to my roommate's choice.

$.30^{*} \quad$ I entered the conversation only when someone asked me a question.

.30* I took a class that did not interest me because it was recommended to me.

$.30^{*} \quad$ I continued to apologize for the minor mistake.

$.29^{*} \quad$ I accepted verbal abuse without defending myself.

$.27^{*} \quad$ I did not talk back when my friend scolded me.

$.27^{*} \quad$ When I stood to speak and the others continued talking, I simply sat down.

$.27^{*} \quad$ I refused to acknowledge gratitude when I did my co-worker a favor.

.26* When the three of us set out on the journey, I took the back seat of the car.

.25* I nodded silently when a teacher told me that he wouldn't change my grade.

$.24^{*} \quad I$ let my friend decide which jacket I should buy.

$.24^{*} \quad$ I agreed I was wrong, even though I wasn't.

$* * * p<.001$.

${ }^{* * p} p<.01$.

${ }^{*} p<.05$. 


\section{Fva- and Dominant Acts}

The Fva- scale (verbal passive-aggressive) was correlated with reported performance of each act of the two act reports. The correlations with dominant acts reaching significance (two-tailed test) beyond the .05 level are shown in Table III.

These acts appear to be similar to the set of acts shown in Table I, although they are fewer in number. Boasting about one's accomplishments, ridiculing others publicly, yelling in order to get one's way, blaming others when things went wrong, hitting others, and making decisions without consulting the others involved in them, all appear to connote the aggressive narcissism characteristic of unmitigated agency. Interestingly, the highest single correlate for the female sample $(+.48)$ was "I gave him the silent treatment when I was upset." This act appears to be a prototype of passive-aggressiveness, a finding that lends considerable credence to the scale name.

Table III. Dominant Act Correlates of Fva- (Verbal Passive-Aggressiveness)

\begin{tabular}{ll}
\hline $\mathrm{r}$ & \multicolumn{1}{c}{ Males $(N=58)$} \\
$.39^{* *}$ & I became angry when my suggestion was not accepted. \\
$.36^{* *}$ & I boasted about my accomplishments. \\
$.34^{*}$ & I made decisions without consulting the others involved in them. \\
$.33^{*}$ & I quickly corrected my friends's mistake publicly. \\
$.28^{*}$ & I ridiculed her in the presence of a group. \\
$.28^{*}$ & I yelled in order to get my way. \\
$.27^{*}$ & I asked someone else to wash the dishes. \\
$-.32^{*}$ & I introduced a speaker at the meeting. \\
& \\
$.48^{* * *}$ & I gave him the "silent treatment" when I was upset. \\
$.40^{* * *}$ & I blamed others when things went wrong. \\
$.36 * *$ & I hung up the phone on my lover. \\
$.34^{*}$ & I became angry when my suggestion was not accepted. \\
$.29 *$ & I hit someone who annoyed me. \\
$.27 *$ & I made decisions without consulting the others involved in them. \\
$-.29^{*}$ & I am active in many community and campus activities. \\
$-.26 *$ & I voiced my opinion in a large class. \\
\hline$* * * p<.001$. &
\end{tabular}


Fva- and Submissive Acts

Table IV shows the submissive acts that correlate significantly with the Fva- scale.

As shown in Table IV, the Fva- scale correlates significantly with a number of submissive acts, particularly for the female sample. However, the masochistic element, present with the Fc- scale, is not seen as clearly in this set of acts. Instead, the acts appear to convey the passivity commonly associated with submissive actions. Weeping at the failure to solve a simple problem, not participating in group discussions, avoiding eye contact, abandoning work to go out with friends, and behaving passively in a sexual encounter, all seem to embody simple passivity rather than masochism, self-abnegation, or undue obsequiousness.

Table IV. Submissive Act Act Correlates of Fva- (Verbal Passive-Aggressiveness)

\begin{tabular}{ll}
\hline$r$ & \multicolumn{1}{c}{ Males $(N=55)$} \\
$.39^{* *}$ & I wept when I couldn't solve the simple problem. \\
$.34^{* *}$ & I continued to apologize for the minor mistake. \\
$.29^{*}$ & I drank a lot of alcohol when I was upset at not getting the job. \\
$.28^{*}$ & I killed a fly when he asked me to \\
$-.27^{*}$ & I did not talk back when my friend scolded me. \\
& \\
$.40^{* * *}$ & I went along with the group reluctantly, rather than disagree. \\
$.34^{* *}$ & I avoided direct eye contact when the shop clerk spoke to me. \\
$.32^{* *}$ & I continued my schooling because my father wanted me to. \\
$.30^{*}$ & When I stood to speak and the others continued talking, I simply sat down. \\
$.29^{*}$ & I was not able to tell my friend that I was angry with her. \\
$.29^{*}$ & I changed my clothes when the others made fun of my attire. \\
$.28^{*}$ & I walked out of the store knowing that I had been short-changed. \\
$.27^{*}$ & I abandoned my homework to go out with friends. \\
$.26^{*}$ & I did not participate in the group's discussion of the project. \\
$.26^{*}$ & I was passive in the sexual encounter. \\
$-.37^{* *}$ & I used my car for the group trip and didn't ask for gas money from the others. \\
$-.34^{* *}$ & I picked up a visitor from the airport, even though bus transportation was \\
$-.26^{*}$ & I did not complain when someone used my car without asking permission. \\
$-.24^{*}$ & I let a casual acquaintance borrow my record albums. \\
\hline
\end{tabular}

$* * * p<.001$.

$* * p<.01$.

${ }^{*} p<.05$. 


\section{DISCUSSION}

To summarize, this study examined the dominant and submissive acts that significantly correlated with the Spence et al. (1979) scales of unmitigated agency, unmitigated communion, and verbal passive-aggressiveness. For the M- scale, high scorers more often report performing acts involving self-enhancement, self-assertion, and separation from the group. Sex differences in the tenor of these acts suggest that agentic males tend to be coolly manipulative (e.g., persuading and managing others), while the females appear to express unmitigated agency through more acrimonious acts (e.g., by yelling and complaining). Corrrelations with Fc- indicate that high scorers accept abuse from others without responding, fail to engage in normatively appropriate agentic responses to insults, and perform acts that they do not wish to perform - the essential features that characterize unmitigated communion. Act correlates of the Fva- scale appear to reflect unmitigated agency, but are not readily assimilated to the concept of unmitigated communion; instead, the correlates with the submissive acts convey simple passivity and do not appear to contain elements of masochism.

These results extend the constructs of unmitigated agency and unmitigated communion, as measured by the EPAQ, by exploring the acts employed in their manifestation. The acts correlating significantly with the Spence et al. (1979) scale of unmitigated agency reflect well the properties attributed to this concept by Bakan (1966). Specifically, the formation of separations is implicated in acts such as making decisions without consulting others involved in them and in quickly correcting a friend's mistake publicly. Self-protection is observed in the acts of bluffing one's way out of an embarrassing situation and protesting when others cut into line. Narcissistic self-assertion is prominently featured in the acts of telling others to perform one's menial tasks, yelling and using fists to get one's way, and refusing to accept compromises. Together, these acts appear to sacrifice group harmony for the goal of self-projection.

This study also uncovers act manifestations of unmitigated communion. The submissive acts of tolerating insults, humiliation, and scolding imply the absence of normatively appropriate agentic responding. Giving up vacation wishes in deference to those of others, continuing schooling due to parental pressure, eating out when not hungry, and agreeing that one is wrong (even though not wrong) convey a degree of self-subjugation to the wishes and requisites of the group that approaches masochism.

Conceptually, these findings support Wiggin's (1979) placement of masochism from the Leary (1957) system of interpersonal variables at the submissive pole of the dominance-submissiveness axis (see also Wiggins \& Holzmuller, 1978, 1981; Wiggins, 1982; Wiggins \& Pincus, 1989). The maso- 
chistic person, according to Leary (1957), avoids potentially conflict-laden areas by exhibiting interpersonal weakness, submissiveness, and passivity. Self-punitive timidity, manifested by the shunning of conflict, thus may function to perserve group harmony. But one may reasonably question whether masochistic actions are actually beneficial to the group, and thus communal in the true sense of the concept. Does it really facilitate group cohesion to tolerate humiliation, scolding, and abuse? Does society benefit from individuals who permit themselves to be short-changed? Second, although the overt behavior entails renunciation of the self, several authors (e.g., Leary, 1957; Menaker, 1956) have conceptualized the function of masochistic behavior as actually contributing to the security of the individual, and therefore as involving self-gain. A demeanor of diffidence subjectively may be the safest and least dangerous position for some persons to adopt, serving to avoid the potential anxiety entailed by confrontation (Sloman \& Price, 1987). Expressions of unmitigated communion may entail costs and benefits at several levels of analysis.

The Fva- scale, purporting to measure verbal passive-aggressiveness, correlates with acts within the domains of both dominance and submissiveness. The dominant act correlates entail boasting about one's accomplishments, becoming angry at suggestions not accepted by the group, making decisions without consulting the others involved in them, correcting friends' mistakes publicly, hitting others, and blaming others when things go wrong. These acts embody the aggressive narcissism characteristic of unmitigated agency. The submissive act correlates involve weeping at the failure to solve a simple problem, going along with the group reluctantly, killing a fly upon request, avoiding eye contact, abandoning homework to go out with friends, failing to participate in group discussions, and exhibiting passivity in sexual encounters. These acts appear to convey simple passivity, and contain fewer of the masochistic and self-effacing components seen with the acts correlated with Fc-. Finally, the act "I gave him the 'silent treatment' when I was upset," the strongest correlate of the Fva- scale for females, suggests the intent to inflict punishment through passivity, and therefore may be viewed as a prototype of passive aggression. Together, these sets of dominant and submissive acts provide striking validation for the Fva- scale.

In addition to identifying the acts linked with unmitigated agency and unmitigated communion, the results have several further conceptual implications. First, they suggest that the new Spence et al. (1979) scales of the negative components of masculinity and femininity possess considerable predictive power and construct validity. The act-correlates of these scales are particularly noteworthy in that the prediction of single acts from personality measures is typically quite low (Buss \& Craik, 1980; Fishbein \& Ajzen, 1974; Jaccard, 1974). And the content of the act-correlates corresponds well to the surface meaning of the scales, suggesting that these new scales are accurately named. 
The present method of examining the acts used in the expression of various dispositions also provides a novel technique for the conceptual analysis of test scores (Gough, 1965). First, it can yield direct information concerning how well a given test accurately predicts behavior in the domain it purports to assess. Second, by examining the coherence among the act-correlates, one can more incisively conceptualize the underlying psychological dimensions inherent in a test. The present study, for instance, indicates that masochism may underly behavioral expressions of unmitigated communion. And third, unexpected or serendipitous findings, provided by act-correlates not anticipated a priori on conceptual grounds, may reveal novel facets of a test that contribute to more comprehensive conceptualizations of the domain under study.

The finding that males and females tend to express the negative components of masculinity and femininity through somewhat different acts raises an additional conceptual issue. It echoes the finding by Buss (1981) that males and females tend to employ different (although overlapping) sets of acts in their manifestations of dominance. Taken together, these studies lend support to Locksley and Colten's (1979) suggestion that surface equivalence between the sexes in item endorsement does not necessarily imply underlying construct equivalence, but clearly additional evidence is needed to substantiate this claim.

Although the results illustrate the usefulness of examining in detail the acts entailed by various personality measures, a major limitation of the present study is that recorded performance of the acts was obtained through self-report. Future research could turn to observational studies by employing the sets of acts recorded by family, friends, or trained observers. Such studies could powerfully corroborate the expressions of unmitigated agency and unmitigated communion found in this study, and may yield more subtle exemplars of these constructs.

\section{REFERENCES}

Bakan, D. (1966). The duality of human existence. Chicago: Rand McNally.

Baruch, G. K., Barnett, R. C., \& Rivers, C. (1983). Lifeprints: New patterns of love and work for today's women. New York: New American Library.

Block, J. H. (1973). Conceptions of sex roles: Some cross-cultural and longitudinal perspectives. American Psychologist, 28, 512-526.

Buss, D. M. (1981). Sex differences in the evaluation and performance of dominant acts. Journal of Personality and Social Psychology, 40, 147-154.

Buss, D. M. (1989). Conflict between the sexes: Strategic interference and the evocation of anger and upset. Journal of Personality and Social Psychology, 56, 735-747.

Buss, D. M., \& Craik, K. H. (1980). The frequency concept of disposition: Dominance and prototypically dominant acts. Journal of Personality, 48, 379-392.

Carlson, R. (1971). Sex differences in ego functioning: Exploratory studies of agency and communion. Journal of Consulting and Clinical Psychology, 37, 267-277. 
Chodorow, N. (1978). The reproduction of mothering: Psychoanalysis and the sociology of gender, Berkeley: University of California Press.

Erikson, E. (1964). Inner and outer space: Reflection on womanhood. Daedalus, 93, 1-25.

Fishbein, M., \& Ajzen, I. (1974). Attitudes toward objects as predictors of single and multiple behavioral criteria. Psychological Review, 81, 59-74.

Freud, S. (1950). Beyond the pleasure principle. New York: Liversight Publishing Corporation.

Gough, H. G. (1965). Conceptual analysis of psychological test scores and other diagnostic variables. Journal of Abnormal Psychology, 70, 294-302.

Guttman, D. L. (1965). Women and the concept of ego strength. Merrill-Palmer Quarterly, $11,229-240$.

Jaccard, J. J. (1974). Predicting social behavior from personality traits. Journal of Research in Personality, 7, 358-367.

Leary, T. (1957). Interpersonal diagnosis of personality. New York: Rondal Press.

Locksley, A., \& Colten, M. E. (1979). Psychological androgyny: A case of mistaken identity? Journal of Personality and Social Psychology, 37, 1017-1031.

Malley, J. E. (1989). The importance of agency and communion for well-being: Individual differences in needs and experiences. Paper presented at the American Psychological Association, New Orleans, August.

Malley, J. E., \& Stewart, A. J. (1988). Women's work and family roles: Sources of stress and sources of strength. In S. Fisher \& J. Reason, (Eds.), Handbook of Life Stress, Cognition, and Health, New York: Wiley, pp. 175-191.

Menaker, E. (1953), Masochism - a defense reaction of the ego. Psychoanalysis Quarterly, 22, $205-220$.

Parsons, T., \& Bales, R. F. (1955). Family socialization and interaction process. Glencoe: Free Press.

Sloman, L., \& Price, J. S. (1987). Losing behavior (yielding subroutine) and human depression: Proximate and selective mechanisms. Ethology and Sociobiology, 8, 99S-109S.

Spence, J. T., \& Helmreich, R. L. (1978). Masculinity and femininity: Their psychological dimensions, correlates and antecedents. Austin: University of Texas Press.

Spence, J. T., Helmreich, R. L., \& Holahan, C. K. (1979). Negative and positive components of psychological masculinity and femininity and their relationships to self-reports of neurotic and acting out behaviors. Journal of Personality and Social Psychology, 37, 1673-1682.

Stewart, A. J., \& Malloy, J. E. (1987). Role combination in women: mitigating agency and communion. In F. Crosby (Ed.), Spouse, parent, worker: on gender and multiple roles. (pp. 44-62). New Haven, CT: Yale University Press.

Stewart, A. J., \& Salt, P. (1981). Life stress, life styles, depression, and illness in adult women. Journal of Personality and Social Psychology, 40, 1063-1069.

Veroff, J., Kulka, R., \& Douvan, E. (1981). The inner American: A self-portrait from 1957-1976, New York: Basic Books.

Wiggins, J. S. (1979). A psychological taxonomy of trait-descriptive terms: The interpersonal domain. Journal of Personality and Social Psychology, 37, 395-412.

Wiggins, J. S. (1982). Circumplex models of interpersonal behavior in clinical psychology. In P. C. Kendall, \& J. N. Butcher, (Eds.), Handbook of research methods in clinical psychology, New York: Wiley.

Wiggins, J. S., \& Holzmuller, A. (1978). Psychological androgyny and interpersonal behavior. Journal of Consulting and Clinical Psychology, 15, 67-80.

Wiggins, J. S., \& Holzmuller, A. (1981). Further evidence on androgyny and interpersonal flexibility. Journal of Research in Personality, 15, 67-80.

Wiggins, J. S., \& Pincus, A. (1989). Conceptions of Personality Disorders and dimensions of personality. Psychological Assessment: A Journal of Consulting and Clinical Psychology, 1, 305-316.

Witkin, H. A. (1974). Social conformity and psychological differentiation. International Journal of Psychology, 9, 11-29. 